https://doi.org/10.30843/nzpp.2018.71.144

\title{
Differences in insect anatomy may affect tolerance to the fumigant ethanedinitrile
}

\author{
Godwin N. Gidiglo ${ }^{1,2, \star}$, Adriana J. Najar-Rodriguez ${ }^{1}$, Matthew K.D. Hall ${ }^{1,3}$, Maria A. Minor ${ }^{2}$, and Qiao \\ Wang $^{2}$ \\ ${ }^{1}$ The New Zealand Institute for Plant \& Food Research Ltd, Private Bag 11600, Palmerston North, New Zealand \\ ${ }^{2}$ Institue of Agriculture \& Environment, Massey University, Private Bag 11222, Palmerston North 4442, New \\ Zealand \\ ${ }^{3}$ Apreso, Palmerston North, New Zealand \\ ${ }^{*}$ Corresponding author: g.gidiglo@massey.ac.nz
}

Ethanedinitrile $(\mathrm{EDN})$ is a potential alternative fumigant to methyl bromide for the phytosanitary treatment of timber and logs. Previously, adult golden-haired bark beetles (Hylurgus ligniperda) have shown high rates of tolerance to EDN, while all life stages of burnt-pine longhorn beetles (Arhopalus ferus) were highly susceptible. These results suggest that the fumigant mode of action might be species-specific and more complex than previously thought. Therefore, the anatomy of these beetles was examined to investigate potential differences in EDN toxicity related to these insect traits. The mesothoracic and fourth abdominal cuticles of 20 individuals were measured and compared across the two species. Spiracle sizes of 20 adult insects were also measured and compared across and within species. Of the two species, $A$. ferus had the thicker dorsal thoracic and abdominal cuticle. Adults of $A$. ferus had also the larger total spiracle area. These results provide important information to help explain the observed differences in EDN tolerance across the two species. Further work will test the main route of entry of EDN into the bodies of target insects and additional effects on EDN on insect behaviour.

https://doi.org/10.30843/nzpp.2018.71.147

\section{Comparing the toxicity of two fumigants to insects from the field vs laboratory - does insect origin matter?}

Adriana J. Najar-Rodriguez ${ }^{*}$ Matthew K.D. Hall, Catherine R. Wilks, Anthony R. Adlam, Sam Brierley, Steven Burgess and Graeme K. Clare

The New Zealand Institute for Plant \& Food Research Ltd, Private Bag 11600, Palmerston North, New Zealand ${ }^{*}$ Corresponding author: adriana.najar-rodriguez@plantandfood.co.nz

The golden-haired bark beetle, Hylurgus ligniperda (F.), is a common forest insect which may be associated with pine (Pinus radiata D.Don) logs exported from New Zealand. We tested the dosemortality responses of $H$. ligniperda adults, from two different origins (field vs laboratory), to methyl bromide (MB), the most widely used fumigant worldwide; and to ethanedinitrile (EDN), a potential alternative to $\mathrm{MB}$. Naked insects were fumigated with either $\mathrm{MB}$ or $\mathrm{EDN}$ at $10^{\circ} \mathrm{C}$ for 4 and 3 hours, respectively. Laboratory adults had been reared on artificial diet under controlled conditions for $>10$ generations. Field adults, by contrast, had been recently collected from Lindgren funnel traps with lures of alpha-pinene and ethanol. Tolerance to the two fumigants tested was significantly different, according to the origin of the insects, with field-collected adults being less tolerant to MB and EDN than laboratory-reared ones. The implications of our results for the development of disinfestation schedules for New Zealand export logs will be discussed. 